\title{
Моделирование реальных опционов для определения оптимальной структуры корпоративного капитала
}

\begin{abstract}
Анисин А.A. ${ }^{7}$
В статье рассмотрена проблема оптимизаџии структуры капитала. Теория структуры капитала появилась в трудах Франко Модильяни и Мертона Миллера. В настоящее время не существует единого подхода к решению этой проблемы. Современные концепции теории структуры капитала предполагают наличие альтернативных подходов $к$ определению оптимальной структуры капитала. Мы использовали теорию компромисса как теоретическую основу для нашего исследования. На основе теории компромисса мь попробуем заложить фундамент для построения практически значимых моделей с учетом достоинств других теоретических взглядов для управления структурой капитала корпорачий. Для определения оптимальной структуры капитала мы рассмотрели оценку средневзвешенной стоимости капитала, используя модели иенообразования опщионов. Метод оценки условных требований в данном случае можно применить для определения величины собственного капитала с учетом риска банкротства. Однако мы можем определить оптимальное значение структуры капитала, только если в процессе моделирования принять во внимание наличие агентских издержек и издержек финансовых затруднений.
\end{abstract}

JEL: $G 32$

Ключевые слова: финансовая политика, финансовый риск и риск менеджмент, оптимальная структура капитала, структура собственности, реальные опщионы

До конца 50-х годов прошлого века теории структуры капитала как таковой не существовало. В 1958 году будущие нобелевские лауреаты Франко Модильяни и Мертон Миллер опубликовали работу [Modigliani F., Miller M., 1958], в которой заложили основы теории структуры капитала. Основным постулатом их теории является то, что стоимость корпорации не зависит от структуры капитала. Так появилась базовая модель МодильяниМиллера. Позднее Модильяни и Миллер дополнили свою модель [Modigliani F., Miller M., 1963], приняв во внимание налогообложение корпораций налогом на прибыль, результатом чего стала расширенная модель Модильяни-Миллера. Франко Модильяни и Мертон Миллер определили влияние эффекта налогового щита на стоимость корпораций, но не смогли сформировать полноценной и пригодной для практического использования теории. Применение расширенной модели Модильяни-Миллера давало парадоксальный вывод о том, что структура капитала является оптимальной при приближении величины финансового рычага к бесконечности.

Целью нашего исследования является создание основы для использования теории структуры капитала в управлении корпорацией. Для достижения указанной цели необходимо обозначить пути построения практически значимых моделей определения оптимальной структуры корпоративного капитала, которые позволят консолидировать современные взгляды на структуру капитала и выработать единый подход к ее оптимизации.

Современные концепции теории структуры капитала предполагают несколько альтернативных подходов к существованию оптимальной структуры капитала. В качестве

\footnotetext{
${ }^{7}$ Аспирант НОУ ВПО Омская гуманитарная академия. 
теоретической основы для нашего исследования мы использовали теорию компромисса и на ее базе попробуем заложить основы построения практически значимых моделей, учитывающих достоинства других теоретических взглядов, для управления структурой капитала корпораций. Статическая теория компромисса утверждает, что для любой корпорации в любой момент времени существует такое значение структуры капитала, при котором его средневзвешенная стоимость была бы максимальной. Такая структура капитала называется оптимальной. Целью динамической теории компромисса является определение пути для достижения оптимальной структуры капитала.

Как мы уже отметили, для определения оптимальной структуры капитала будет использоваться подход оценки условных требований. Для обоснования использования этого подхода проанализируем денежные потоки приобретения корпорации.

Приобретение корпорации в целом предполагает приобретение всех активов и обязательств корпорации, с учетом того, что обязательства необходимо будет погасить в течение определенного периода времени. Тогда покупатель, уплачивая в исходный момент Т $=0$ стоимость корпорации (C), получает в свое распоряжение все ее активы (A), с необходимостью погасить через определенный период времени (t) обязательства корпорации (D). Если за период $t$ оценка А станет меньше определенного уровня $\left(\mathrm{A}_{\mathrm{B}}\right)$, то корпорацию можно считать банкротом. Тогда покупатель терпит убыток в размере С. Во всех остальных случаях можно условно считать, что покупатель остался в своих правах на корпорацию к моменту $\mathrm{T}=\mathrm{t}$. Рассмотренная ситуация доказывает, что собственный капитал можно оценивать как опцион покупателя. Таким образом, мы определили возможность применения метода реальных опционов для оценки стоимости капитала. Проблемой в этом случае является определение величины $\mathrm{C}$ - стоимости опциона.

К настоящему времени появился ряд моделей, построенных на основе дифференциального уравнения Блэка-Шоулза-Мертона, первой из которых была модель Мертона [Merton R., 1974]. Однако Роберт Мертон построил весьма упрощенную модель, которая была предназначена скорее для управления кредитными рисками, нежели для управления структурой капитала. Модель Мертона оценивала вероятность банкротства с теми же допущениями, что и в модели ценообразования опционов Блэка-Шоулза; среди них в числе прочего были допущения об эффективности рынка капитала и о рискнейтральности оценок участников этого рынка.

Допущение о совершенстве рынка капитала предполагает равную обеспеченность участников рынка информацией и объективность сложившихся на рынке цен, т.е. их соответствие реальным условиям хозяйствования, реальному имущественному положению и реальным результатам деятельности хозяйствующих субъектов, котируемых на организованном рынке ценных бумаг. В действительности рынок капитала далеко не совершенен, что наглядно продемонстрировал финансовый кризис, начавшийся в 2008 году. Участники рынка в разной степени обеспечены информацией о положении дел на нем. На рынке существует финансовый арбитраж, а спекулятивные интересы участников рынка влияют на изменение текущих цен в необходимом для спекулянтов направлении, что отдаляет биржевые котировки от реального положения вещей. Также необходимо отметить, что оценки на рынке капитала в действительности не являются риск-нейтральными. Таким образом, становится понятным, что активные спекуляции на организованном рынке ценных бумаг искажают цены, а значит, мы не можем использовать рыночные оценки для управления структурой капитала.

Альтернативой рыночных оценок являются только балансовые, полученные для управленческих целей. Применение балансовой оценки имеет для нас больший приоритет, чем применение рыночной, по причинам указанным выше, а также из-за возможности применения балансовой оценки для любой корпорации, но не каждым заинтересованным лицом, а только обладателем необходимой информации. Рыночную же оценку можно применять только в отношении корпораций, которые на постоянной основе котируются на организованном рынке ценных бумаг; при этом указанной возможностью обладает любое 
заинтересованное лицо.

И балансовая, и рыночная оценки несут риск несправедливости. Балансовая оценка может быть несправедливой по причине несправедливости оценки активов корпорации. Рыночная оценка может быть несправедливой по причине ограниченности информации о финансовом состоянии и результатах деятельности, поступающей на рынок в отношении исследуемой корпорации.

В качестве еще одного варианта модели управления структурой капитала можно рассмотреть модель Хартвига Леланда [Leland H., 1994], который модифицировал уравнение Блэка-Шоулза-Мертона и решил его относительно оценки заемного капитала. Х. Леланд предусмотрел в своей модели издержки банкротства, тем не менее модель обладает следующими недостатками:

- существует допущение об эффективности рынка капитала;

- сохранено допущение о равной непредрасположенности к риску участников рынка;

- модель совершенно не учитывает фактор времени.

В 1996 году Х. Леланд вместе с К. Тофтом опубликовали более совершенную модель [Leland H., Toft K., 1996], в которой фактор времени был учтен, но остальные недостатки остались. Помимо указанных моделей дополнительно можно выделить следующие:

- модель Фэна - Сандерсена [Fan H., Sundaresan S., 2000];

- модель Франсуа-Мореллека [Fracois P., Morellec E., 2004];

- модель Ю Оу-Янга [Ju N., Ou-Jang Н.. 2006];

- модель Броди-Чернова—Сандерсена [Broadie M., Chernov M., Sundaresan S., 2006].

Все указанные модели также применяют допущения об эффективности рынка капитала и о риск-нейтральности оценок участников рынка. Применение подобных допущений является обоснованным, если в качестве цели устанавливается оценка состояния хозяйствующего субъекта вне корпорации, т.е. инвесторами, кредиторами и другими участниками рынка. В этом случае внешние агенты, заинтересованные в получении достоверной информации о финансовом состоянии и результатах деятельности корпорации, будут больше доверять оценке на организованном рынке ценных бумаг, нежели оценке в финансовой отчетности.

Наш взгляд на структуру капитала позиционируется на интересах, прежде всего, внутренних пользователей информации о финансовом состоянии и результатах деятельности. Мы по указанным выше причинам считаем, что необходимо построить модель для управления структурой капитала изнутри корпорации, менеджеры которой будут способны использовать для оценки капитала управленческие данные, недоступные внешним пользователям информации. Поэтому мы считаем необходимым в этом случае использовать балансовые оценки, сформированные по данным не финансовой, а управленческой отчетности.

Для построения модели, адекватной к использованию в управлении структурой капитала корпораций, мы также предлагаем модифицировать дифференциальное уравнение Блэка-Шоулза-Мертона в соответствии с обозначенными условиями. Введем следующие допущения:

- непрерывная доходность активов подчиняется процессу Ито и нормально распределена во времени;

- дивиденды в течение расчетного периода $\mathrm{t}$ не выплачиваются из величины собственного капитала;

- величина заемного капитала в течение расчетного периода t остается постоянной.

Тогда необходимое нам дифференциальное уравнение будет выглядеть следующим образом:

(1)

$\mathrm{E} \cdot \mathrm{k}_{\mathrm{A}}=\frac{\partial E}{\partial t}+\mathrm{k}_{\mathrm{A}} \cdot A \cdot \frac{\partial E}{\partial A}+\frac{\partial^{2} E}{\partial A^{2}} \cdot \frac{\sigma_{A}^{2}}{2} \cdot A^{2}$,

где:

Выпуск \#1(9), 2009 
$\mathrm{k}_{\mathrm{A}}$ - непрерывная доходность активов;

$\sigma_{\mathrm{A}}-$ волатильность активов;

$\mathrm{E}$ (Equity) - значение собственного капитала в момент $\mathrm{T}=0$;

A (Assets) - значение активов в момент T $=0$;

$\mathrm{t}$ - продолжительность расчетного периода.

Решим уравнение (1) со следующим краевым условием:

$E=\max (A-D, 0)$,

где:

D (Debt) - заемный капитал.

Доказательство решения уравнения (1) абсолютно аналогично доказательству решения дифференциального уравнения Блэка-Шоулза-Мертона для стоимости опциона покупателя. Решением уравнения (1) будет следующее выражение оценки стоимости собственного капитала в момент $\mathrm{T}=\mathrm{t}$ :

(2)

$$
\begin{aligned}
& E(t)=A \cdot \exp \left(\left(k_{A}-\frac{\sigma_{A}^{2}}{2}\right) \cdot t\right) \cdot N\left(d_{+}\right)-D \cdot N\left(d_{-}\right) \\
& d_{ \pm}=\frac{\ln \left(1+\frac{1}{F L}\right)+\left(k_{A} \pm \frac{\sigma_{A}^{2}}{2}\right) \cdot t}{\sigma_{A} \cdot \sqrt{t}} \\
& N\left(d_{ \pm}\right)=\frac{1}{\sqrt{2 \pi}} \cdot \int_{-\infty}^{d_{ \pm}} \exp \left(-\frac{x^{2}}{2}\right) \cdot \partial x
\end{aligned}
$$

Исходя из формулы (2), в силу действия допущения о постоянстве оценки заемного капитала, мы можем рассчитать оценку активов в момент $\mathrm{T}=\mathrm{t}$ :

$$
A(t)=A \cdot \exp \left(\left(k_{A}-\frac{\sigma_{A}^{2}}{2}\right) \cdot t\right) \cdot N\left(d_{+}\right)+D \cdot N\left(-d_{-}\right)
$$

В формуле (3) выражение N(-d.) показывает вероятность банкротства корпорации в течение расчетного периода t. Величина $k_{A}-\frac{\sigma_{A}^{2}}{2}$ является математическим ожиданием непрерывной доходности активов. Чтобы понять: почему данная величина корректируется на половину квадрата волатильности активов, рассмотрим следующее уравнение:

$$
A(t)=A \cdot \exp (x \cdot t) \Rightarrow x=\frac{\ln A(t)-\ln A}{t},
$$

где:

$\mathrm{x}$ - непрерывная доходность активов.

Учитывая, что разность натуральных логарифмов является случайной величиной, нормально распределенной во времени и подчиняющейся процессу Ито, делаем вывод, что величина $\mathrm{A}(\mathrm{t})$ имеет логнормальное распределение. Исходя из леммы Ито, для получения математического ожидания непрерывной доходности активов ее необходимо уменьшить на половину квадрата волатильности. Дисперсия непрерывной доходности активов будет равна произведению квадрата волатильности и длины расчетного периода. 
Активы в уравнении (1) берутся по балансовой стоимости, определенной в управленческом учете корпорации, что позволяет ликвидировать допущение об эффективности рынка капитала, так как в этом случае из модели устраняется оценка на организованном рынке ценных бумаг. Непрерывная доходность активов определяется исходя из закладываемой в модель рентабельности активов, приведенной к непрерывному виду. Непрерывная доходность активов заменяет безрисковую ставку в модели БлэкаШоулз-Мертона. В настоящей работе мы не будем подробно описывать особенности перехода от риск-нейтральных оценок к реальным условиям. Такой переход в относительно доступной форме описывается у Дж. Халла [Халл Дж. К., 2007].

Отметим, что волатильность активов, оцененных по балансовой стоимости, не является по существу показателем волатильности. Данный показатель позволяет определить среднеквадратическое отклонение колебаний уровня активов через колебания операционных денежных потоков и результатов деятельности корпорации. Для правильной оценки волатильности активов мы должны надежно оценить волатильность собственного капитала $\left(\sigma_{\mathrm{E}}\right)$. Показатели волатильности активов и собственного капитала будут различаться.

За основу при оценке волатильности собственного капитала мы предлагаем взять колебания собственного капитала, связанные с операционной деятельностью, с поправками, отражающими признание доходов и расходов по оплате, а не по отгрузке. В этом случае для оценки волатильности будут анализироваться операционные денежные потоки, динамика которых позволяет более надежно оценить деловой риск, нежели динамика чистой прибыли. Тогда волатильность собственного капитала может быть рассчитана с применением стандартных методов. Волатильность активов можно найти в результате решения следующего уравнения:

$$
\exp \left(\left(k_{E}-\frac{\sigma_{E}^{2}}{2}\right) \cdot t\right)+F L=(1+F L) \cdot \exp \left(\left(k_{A}-\frac{\sigma_{A}^{2}}{2}\right) \cdot t\right)
$$

где:

$\mathrm{k}_{\mathrm{E}}-$ непрерывная доходность собственного капитала.

Непрерывная доходность капитала однозначно определяется из непрерывной доходности активов, так как это взаимосвязанные показатели. При этом, что очевидно по определению, для $\mathrm{FL} \geq 0$ выполняются условия: $\sigma_{\mathrm{E}} \geq \sigma_{\mathrm{A}}$ и $\mathrm{k}_{\mathrm{E}} \geq \mathrm{k}_{\mathrm{A}}$. Более подробно доказательство уравнения (1) в настоящей работе мы рассматривать не будем, так как оно аналогично доказательству формул Блэка-Шоулза-Мертона, которое приводится, например, у Дж. Халла [Халл Дж. К., 2007].

Средневзвешенная стоимость капитала (WACC - Weighted Average Cost of Capital) представляет собой частное от деления совокупности денежных потоков собственников капитала за год на величину авансированного капитала. В нашем случае мы рассмотрим средневзвешенную стоимость капитала как частное от деления совокупности денежных потоков собственников капитала за произвольный период на величину активов в начале периода:

$$
\begin{aligned}
& W A C C_{t}=\frac{E I-1+F L \cdot k_{D} \cdot t}{F L+1} \\
& E I=\frac{E(t)}{E}=\left(\exp \left(\left(k_{A}-\frac{\sigma_{A}^{2}}{2}\right) \cdot t\right)+F L\right) \cdot N\left(d_{+}\right)-F L \cdot N\left(d_{-}\right)
\end{aligned}
$$

где:

FL (Financial Leverage) - финансовый рычаг в момент $\mathrm{T}=0$, равный частному от деления величины собственного капитала на величину заемного капитала. 
Максимизировать величину средневзвешенной стоимости капитала в расчетном периоде, полученную в формуле (5), управляя величиной финансового рычага, не получится. На рис. 1 представлена графическая иллюстрация зависимости средневзвешенной стоимости капитала в расчетном периоде от финансового рычага. Зависимость от FL определена на положительной части числовой оси, ее область значений ограничена снизу и сверху, функция имеет выпуклый, монотонно возрастающий характер на всей своей области определения. Область значений функции сверху ограничена асимптотой, минимальное значение функции достигается при приближении аргумента к нулю.

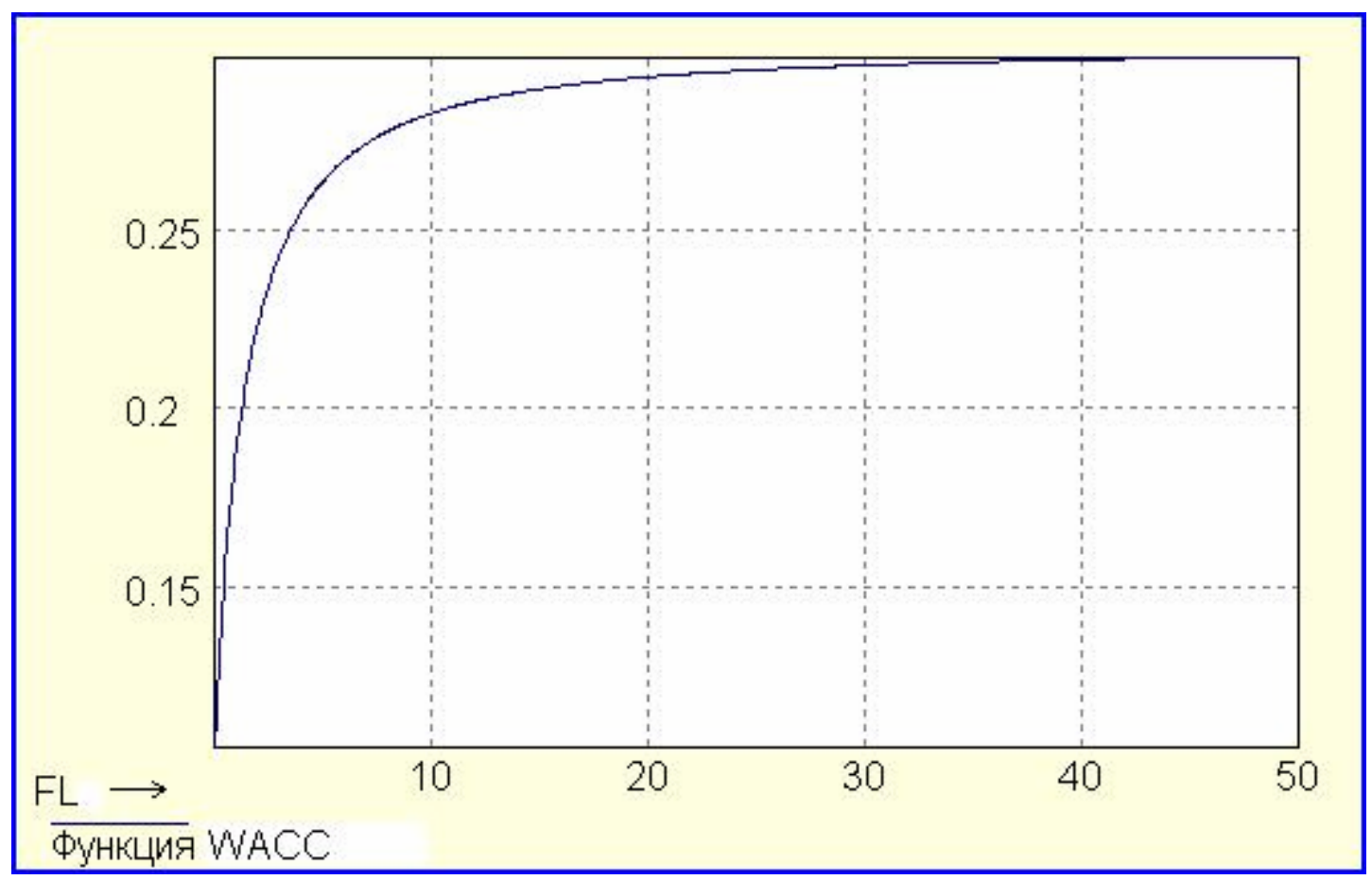

Рисунок 1. График зависимости средневзвешенной стоимости капитала в расчетном периоде от финансового рычага

Из рис. 1 видно, что структура капитала является оптимальной, если он на 100\% состоит из заемного капитала. Таким образом, мы пришли к тем же выводам, что и Франко Модильяни и Мертон Миллер при построении расширенной модели Модильяни-Миллера. Для построения более эффективной модели нам необходимо предусмотреть издержки финансовых затруднений.

Абсолютная величина издержек финансовых затруднений находится в прямо пропорциональной зависимости от величины обязательств корпорации и от вероятности банкротства, так как с ростом обязательств увеличивается вероятность неплатежеспособности, а значит, и банкротства.

Издержки банкротства в целом представляют собой уменьшение стоимости активов, которое не зависит от структуры капитала. Любое банкротство создает отрицательный совокупный денежный поток, не только независимо от соотношения собственного и заемного капитала, но и от вида ответственности собственников. Разница лишь в механизме перераспределения этого общего отрицательного денежного потока, где в любом случае в более выгодном положении оказываются кредиторы, а не собственники.

Также необходимо учитывать, что корпорация может стать банкротом и при более высоком уровне активов, нежели величина заемного капитала. Величина активов, при которой наступает банкротство, зависит от ликвидности активов корпорации. Чем менее ликвидны активы корпорации, тем выше уровень активов, при котором эта корпорация обанкротится, и наоборот. Обозначим уровень активов, при котором наступает банкротство, как $\mathrm{A}_{\mathrm{B}}$; тогда ожидаемые в течение расчетного периода издержки банкротства (ВС - 
Bankruptcy Costs) можно выразить следующим образом:

$$
B C=k_{B} \cdot A_{B} \cdot N\left(-d_{-}\right),
$$

где:

$\mathrm{k}_{\mathrm{B}}$ - доля издержек банкротства в величине активов на момент банкротства (удельные издержки банкротства).

Определение величины удельных издержек банкротства и уровня активов, при котором наступит банкротство, является наиболее трудной задачей. Удельные издержки банкротства можно оценить методами корреляционно-регрессионного анализа на основе эмпирических данных о банкротстве корпораций. В этом случае, определив значения факторов, влияющих на величину удельных издержек банкротства, для исследуемой корпорации, возможна относительно надежная идентификация величины $\mathrm{k}_{\mathrm{B}}$. Уровень активов, при котором наступает банкротство, можно индивидуально определить, проведя глубокий финансовый анализ корпорации и оценив ликвидность активов. Дополнительно отметим, что мы в настоящей работе исходили из допущения о мгновенности события банкротства.

Исходя из уровня ликвидности активов корпорации, можно сделать вывод, что вся величина $\mathrm{A}_{\mathrm{B}}$ в полном объеме покроет обязательства D. Тогда разность между величинами $\mathrm{A}_{\mathrm{B}}$ и $\mathrm{D}$ будет представлять собой издержки ликвидности при банкротстве. Если ввести в действие допущение о постоянстве структуры активов, то частное от деления издержек ликвидности на величину активов корпорации будет постоянной величиной. Преобразуем формулу (5) с учетом издержек финансовых затруднений:

$$
\begin{aligned}
& W A C C_{t}=\frac{E I-1+F L \cdot k_{D} \cdot t}{F L+1}-k_{B} \cdot \frac{A_{B}}{A} \cdot N\left(-d_{-}\right) \\
& d_{ \pm}=\frac{\ln \left(\frac{A_{B}}{A}\right)+\left(k_{A} \pm \frac{\sigma_{A}^{2}}{2}\right) \cdot t}{\sigma_{A} \cdot \sqrt{t}}
\end{aligned}
$$

Величину средневзвешенной стоимости капитала в расчетном периоде, полученную в формуле (6), управляя величиной финансового рычага, максимизировать можно. На рис. 2 представлена графическая иллюстрация зависимости средневзвешенной стоимости капитала в расчетном периоде от финансового рычага с учетом издержек финансовых затруднений. Характер зависимости изменился. У функции появился глобальный максимум и точка перегиба на области определения. Минимальное значение функции зависит от положения уровня горизонтальной асимптоты относительно нуля. 


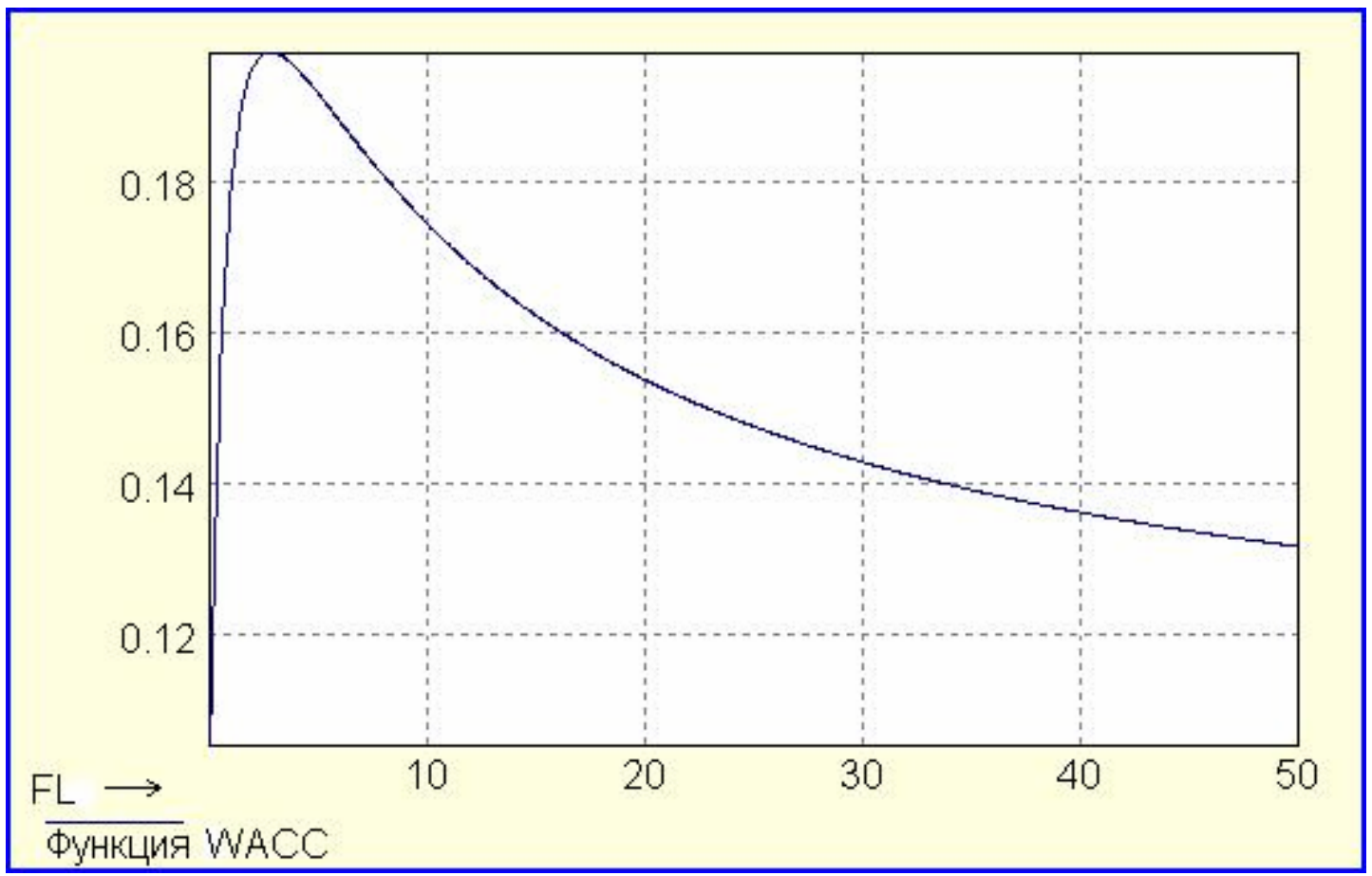

Рисунок 2. График зависимости средневзвешенной стоимости капитала в расчетном периоде от финансового рычага с учетом издержек финансовых затруднений

Таким образом, мы доказали, что определение оптимальной структуры капитала для балансовых оценок, сформированных по данным управленческой отчетности, является возможным. Обозначив рамки определения параметров модели, предусмотрев дополнительные факторы, влияющие на средневзвешенную стоимость капитала, в том числе агентские издержки, рассмотренную нами модель можно расширить. Тем не менее главной проблемой останется получение достоверных оценок параметров модели.

\section{Список литературы}

1. Брейли Р. Принципы корпоративных финансов. М.: ЗАО «Олимп-Бизнес», 2008. $1008 \mathrm{c}$.

2. Бригхэм Ю. Финансовый менеджмент. 10-е изд. СПб.: Питер, 2007. - 960 с.

3. Дамодаран А. Инвестиционная оценка: инструменты и методы оценки любых активов. 4-е изд. М.: Альпина Бизнес Букс, 2007. - 1340 с.

4. Халл Дж. К. Опционы, фьючерсы и другие производные финансовые инструменты. 6е изд. М.: ООО «И.Д. Вильямс», 2007. - 1056 с.

5. Broadie, M., Chernov, M., Sundaresan, S. (2006), Optimal Debt and Equity Values in the Presence of Chapter 7 and Chapter 11, Journal of Finance, 62 (2006) 1341-1377.

6. Fan, H., Sundaresan, S. (2000), Debt Valuation, Renegotiations and Optimal Dividend Policy, Review of Financial Studies, 13 (2000) 1057-1099.

7. Francois, P., Morellec, E. (2004), Capital Structure and Asset Prices: Some Effects of Bankruptcy Procedures, Journal of Business, 77 (2004) 387-411.

8. Ju, N., Ou-Yang, H. (2006), Capital Structure, Debt Maturity, and Stochastic Interest Rates, Journal of Business, 79 (2006) 2469-2502.

9. Leland, H. E. (1994), Corporate Debt Value, Bond Covenants, and Optimal Capital Structure, Journal of Finance, 49 (1994) 1213-1252.

10. Leland, H. E., Toft, K. B. (1996), Optimal Capital Structure, Endogenous Bankruptcy, and the Term Structure of Credit Spreads, Journal of Finance, 51 (1996) 987-1019.

11. Merton, R. (1974), On the Pricing of Corporate Debt: The Risk Structure of Interest Rate, Journal of Finance, 29 (1974) 449-470. 
12. Modigliani, F., Miller, M. (1963), Corporate Income Taxes and the Cost of Capital: A Correction, American Economic Review, 53 (1963) 147-175.

13. Modigliani, F., Miller, M. (1958), The Cost of Capital, Corporation Finance, and the Theory of Investment, American Economic Review, 48 (1958) 261-297. 